\title{
LA DOCTRINA DE LAS 200 MILLAS Y EL DERECHO DEL MAR
}

Bien puede decirse que ninguna otra rama del derecho internacional público ha cambiado más en los últimos cuarenta años que la relativa al derecho del mar. La Conferencia de La Haya de 1930 convocada por la antigua Liga de Naciones con la intención de codificar las leyes del mar y en la que participaron 42 países, llegó a su fin sin haber alcanzado su propósito y todo to que quedó de ella fue la evidente tendencia de los Estados costeros a extender los límites de su jurisdicción marítima, $v$ la existencia de una variedad de medidas concernientes a las aguas territoriales. La supuesta regla de las tres millas fue, según expresión de Gidel, "el ídolo caído" de la Conferencia.

En ausencia de normas internacionates que go. bernaran la utilización del mar como una fuente de riqueza, el mundo entró, entonces, en una nueva era de medidas unilaterales de "auto-protección" adoptadas por los respectivos Estados. Un Memorándum del Secretario General de las Naciones Unidas publicado en 1949 encontró que la acción de los Estados a .adoptar tales medidas era inatacable desde el punto de vista de la justicia internacional, dado que el conflicto de intereses habia frustrado hasta ahora los intentos de codificación y había hecho la adopción de reglas que pudieran ser aceptadas por todas las naciones más difícil en este campo del derecho internacional que en cualquier otro.

Un nuevo intento de codificación se llevó a cabo por la Organización de las Naciones Unidas en las dos conferencias que convocó en Ginebra en 1958 y 1960. Pero tampoco se llegó a un acuerdo sobre el límite de las aguas territoriales. Sin embargo, cuatro convenciones, adoptadas por mayoría, resultaron de la Conferencia de 1958 , de las que la relativa a la plataforma continental es la única que incorpora un nuevo concepto al derecho del mar.

En la continuada ausencia de reglas internacionales, la tendencia de los Estados costeros a extender su jurisdicción ha proseguido y las proclamacio- nes que datan de la década de los años 40 bien puede decirse que están adquiriendo fuerza de costumbre $y$, en todo caso, consolidándose. Al mismo tiempo, el desarrollo de la ciencia y de la tecnología demuestra aún más claramente las posibilidades que ofrece el mar como fuente de alimentación $y$ de riqueza, en general, para la humanidad. En consonancia con este proceso, las Naciones Unidas están otra vez preparando una tercera Conferencia Mun dial sobre el derecho del mar en la que alrededor de 140 países participarán para debatir y resolver, si es posible, las cuestiones y problemas pendientes, así como algunos nuevos que se han suscitado, tales como el desarrollo $y$ aprovechamiento de los fondos oceánicos más allá de los límites jurisdiccionales de los Estados costeros, para el bien común de la humanidad.

\footnotetext{
* Traducida especialmente para nuestra Revista de una transcripción magnetofónica en inglés, publicamos la conferencia que por invitación de la Universidad de Oxford ofreció en el "All Souls College" de ese antiguo centro de estudios, el doctor Enrique García Sayán, el 14 de mayo de 1973, sobre el límite de las 200 millas en el derecho del mar. Presentó al conferenciante ef Profesor principal de Derecho Internacional Público en Oxford, Daniel P. O'Connell, quien destacó el papel del doctor García Sayán, como Ministro de Relaciones Exteriores, en la formulación en 1947 de la tesis peruana $y$, luego, en una sucesión de reuniones internacionales en las que ha participado. Consideramos que la disertación del doctor García Sayán conserva toda su vigencia ante los últimos desarrollos, incluso la Conferencia de Caracas, en cuya primera fase de debates $\vee$ proposiciones (julio-setiembre 1974) la distancia de 200 millas ha sido generalmente aceptada como límite, aunque sin haber cobrado expresión tal consenso en ninguna resolución. Asimismo, conceptuamos que dicha disertación debe haber tenido la virtud de familiarizar con la génesis, fundamentos y progresión de nuestro caso, a un auditorio como el de Oxford, poco propicio a aceptarlo $Y$ en circunstancias en las que Gran Bretaña impugnaba a Islandia, en la llamada "guerra del bacalao", la extensión de la jurisdicción pesquera de esa pequeña isla.
} 
Las proclamaciones del Presidente Truman, 1945.

El movimiento de ideas que siguió a la frustra. da Conferencia de La Haya de 1930, llegó a un punto de consecuencia de gran alcance, con las proclamaciones del Presidente Truman de los Estados Unidos de América del 28 de setiembre de 1945, expresadas en realidad en dos instrumentos distintos, aunque complementarios. El primero declaraba la pertenencia de los Estados Unidos y su "jurisdicción y control" [respecto a los recursus naturales] de la plataforma submarina o zócalo cuntinental, con expresa exclusión de los mares que la cubren. En el. segundo instrumento se declaraba el derecho de los Estados Unidos de establecer "zonas de conservación" para proteger los recursos pesqueros en áreas de alta mar contiguas a sus costas.

Se introdujo de esta manera, unilateralmente, en el vocabulario internacional $y$ se le invistió de autoridad oficial por una de las mayores potencias, el concepto de la plataforma submarina o zocalo continental $y$ el del derecho del Estado costero de establecer en alta mar, áreas de jurisdicción y control para la conservación $y$ utilización de las pesquerias $y$ otros recursos marinos.

Aún cuando el lenguaje de estas proclamaciones del Presidente Truman fue extremadamente cauto, y el concepto de soberanía no es mencionado en ellos -solamente se habla de jurisdicción y control- y por más que el respeto a la libertad de alta mar sea reiterado, hay nociones generales como la de "auto-protección" mencionada en el preámbulo, que estaban llamadas a estimular otras reivindicaciones.

Las proclamaciones Truman no dieron lugar. por lo demás, a observaciones o reparos de parte de otros Estados, que vieron las ventajas que su adopción podía traerles -especialmente a aquellos con extensas plataformas continentales-. Sin embargo, fueron varios países latinoamericanos - México, Argentina, Chile y Perú- los primeros en inspirarse en las proclamaciones del Presidente de los Estados Unidos para formular sus propias declaraciones que iban más allá de la de los Estados Unidos. México por una declaración del 29 de octubre de 1945, reivindicó la plataforma submarina con las riquezas que contiene $y$, además, el aprovechamiento $y$ control de zonas de protección pesquera "independientemente de las distancias que las separa de las cos$\operatorname{tas}^{\prime}$ y "de las que depende el bienestar nacional". La proclamación argentina 111 de octubre de 1946) sin señalar una distancia particular, declaró la soberanía de la nación sobre el zócalo continen- tal y el mar que lo cubre. Chile, por una declaración presidencial (23 de junio de 1947) proclamó la soberanía de la nación sobre el zócalo continental y los mares adyacentes a sus costas hasta una distancia de 200 millas náuticas. Luego vino el Perú. Alineándose con su vecino del sur, Chile, y por algunas razones adicionales que le son propias, también proclamó, por Decreto presidencial del 10. de agosto de 1947, la soberanía y jurisdicción nacionales sobre la plataforma submarina $y$ las aguas que la cubren, así como respecto de una zona de mar adyacente a su línea costera, hasta una distancia de 200 millas náuticas, para reservar, proteger, conservar y utilizar los recursos y riquezas naturales de toda clase que en o debajo de dicho mar se encuentren. Todo esto sin perjuicio de la libre navegación de barcos de cualquier bandera. Se entendió también que la naturaleza exclusiva de la jurisdicción así proclamada no impediría al gobierno peruano el autorizar a nacionales de otros Esta. dos para ejercitar actividades pesqueras dentro de las zona sometida al control del Perú $y$ según las reglamentaciones del régimen peruano.

De esta manera hizo su entrada en el derecha internacional del mar, la soberanía del Estado costero hasta una distancia de 200 millas náuticas. Fue este un nuevo límite jamás pensado antes y ciertamente hubo reservas tanto en el caso de Chile cuanto en el del Perú, de parte de ciertas potencias marítimas (Reino Unido, Estados Unidos) que consideraban al nuevo limite contrario al derecho internacional.

La proclamación del Perú, fue seguida por la de cuatro Estados centroamericanos. Mas ningún otro acto confirmatorio tuvo mayor significación para la doctrina de las 200 millas que la llamada "Declaración de Santiago" firmada en la capital de Chile en junio de 1952 por Chile, Ecuador y Perú. Desde entonces los tres paises han sostenido la soberania que proclaman sobre un área de $\mathbf{2 0 0}$ millas, dentro de todo un sistema subregional, conocido como el Sistema Marítimo del Pacífico Sur, el que cuenta con una Comisión Permanente, un Secretariado General $y$ que ha sido mejorado y consolidado a través de una serie de convenios $y$ resoluciones que hoy forman un cuerpo no sólo de doctrina, sino también de medidas prácticas para la conservación delas especies en esa zona.

En el corto tiempo a mi disposición no puedo describir, como no sea muy brevemente $y$ en sus grandes lineamientos, el desarrollo de una doctrina 
con la que nueve países latinoamericanos están hoy asociados por actos de derecho positivo, $y$ en la que todos los otros, como veremos, han convenido de algún modo. Sin embargo, antes de entrar a ocuparme de este proceso, desearía concentrarme en el principal propósito de esta disertación que es el de examinar los factores y circunstancias que llevaron a las proclamaciones de $\mathbf{2 0 0}$ millas $v$, también, las va rias razones geográficas, biológicas, económicas, so ciales $y$ jurídicas, alegadas en su apoyo. Creo que ningún otro caso ilustra mejor el razonamiento que el caso de mi propio país, el Perú. Porque Perú -poseedor posiblemente, de los más ricos campos pesqueros del planeta- ha llegado a ser, desde 1963, al amparo de su límite de 200 millas, la pri mera nación pesquera del mundo, proveyendo así la más convincente evidencia en favor de las razones en que se basa nuestro planteamiento.

\section{Actos de derecho positivo.}

Las proclamaciones iniciales a las que me he referido, de Estados Unidos, México, Argentina y Chile, diferían en su contenido $y$ alcance, pero derivaban todas no tanto de motivaciones políticas o de doctrinas preconcebidas, como de consideraciones uconómicas de orden práctico. Ellas dejaron estable. cida, de una parte, la pertenencia del Estado costero respecto de los recursos de la plataforma submarina - zócalo continental $\vee$ de otra la existencia bajo distintas denominaciones $y$ atributos, de una competencia exclusiva o preeminente del Estado costero respecto de áreas especificas consideradas antes como de alta mar, contiguas a sus costas, en la extensión necesaria para asegurar la conservación y el uso para beneficio de su población, de los recursos vivos y minerales existentes en esas áreas.

En vista de la fundamentación de estas proclamaciones se vió claro que estábamos en los albores de una nueva era en el derecho internacional marítimo. En el caso del Perú, la situación tenía que ser mirada con el mayor cuidado, en razón de sus intereses $y$ aspectos particulares.

\section{El mar peruano.}

Un conjunto de circunstancias naturales favorables han hecho del mar adyacente a las costas del Perú - de una logitud de cerca de mil millas- uno de los más ricos en recursos biológicos. Entre estas circunstancias debe mencionarse las características geolćgicas y morfológicas de nuestra costa, la coiriente fría que corre a su largo proveniente del Antártico, y las substancias minerales y orgánicas que descargan en el mar los ríos que descienden de los Andes o que son traídas por los vientos, desde las montañas. La concurrencia de éstos y otros factores, que no trataré de describir ahora, da a las aguas adyacentes a nuestra costa su extraordinario poder vital y hacen así de este mar uno de los más ricos en recursos pesqueros.

\section{La tierra y la nutrición.}

Así como la naturaleza fue pródiga al llenar los mares contiguos a nuestra costa con abundantes recursos, del mismo modo puede decirse que fue avara en lo que respecta a la tierra. El Perú cubre $1^{\prime} 250,000$ kilómetros cuadrados, o sea una extensión aproximadamente igual a la de España, Portugal, Francia, Bélgica, Holanda y Dinamarca juntas y tiene, según el último censo, cerca de catorce millones de habitantes. ¿Qué significa todo esto para el Perú? Una enorme tarea por realizar. Los índices de crecimiento de la población indican que se habrá llegado a los veinte millones de habitantes en 1980.

Frente a esta fuerte presión demográfica, el problema de la insuficiencia de recursos alimenticios se está haciendo agudo. El cinturón verde que corre a lo largo de la costa de Sudamérica se detiene en el Perú. La costa peruana es un desierto; sólo $3.1 / 2$ o/o de su superficie está bajo cultivo por medio de sistemas de irrigación. Además, los Andes cubren una gran parte de nuestro territorio $y$ constituyen una barrera formidable a las comunicaciones. De aquí que la tierra cultivada sea escasa $y$ no provea a nuestro pueblo de suficiente alimentación.

\section{Compensación de los recursos pesqueros.}

En esta situación de desnutrición la abundancia de los recursos pesqueros provee de una fuente fácilmente accesible de proteínas, grasas, minerales $y$ vitaminas para nuestra población sub-alimentada. Aunque los habitantes de nuestro territorio que viven cerca del mar han usado esta fuente de alimentación desde tiempos inmemoriales, es solamente en los últimos treinta años aproximadamente, que en el Perú y otros países americanos se ha tomado plena conciencia de la magnitud e importancia del mar 
como fuente de alimentación. La industria pesquera moderna sólo tiene esa antigüedad. Antes de ella, los métodos empleados eran primitivos e individua. les.

\section{Las aves guaneras.}

Intimamente relacionada con nuestra ecología marítima y con el marco socio-económico del hombre en el Perú, está el singular fenómeno de las aves productoras del guano, que viven en las islas $y$ pro montorios de nuestra costa. Los depósitos de estas aves -de los que un promedio de 300,000 toneladas se ha extraído en los años máximos - constituyen un fertilizante natural de un alto contenido de nitrógeno y fosfatos, que llegó a proveer a la agricultura peruana de cerca del $90 \%$ o de sus requerimientos en la materia. Ellas también proveen al Estado, a quien pertenecen estos recursos, de una fuente de ingresos. Un pequeño pez, la anchoveta (diferente de la anchoa europea) es el principal alimento para estas aves. Sin embargo, a pesar de su abundancia, la anchoveta estaría amenazada de extinción por la pesca indiscriminada que de ella se hace para convertirla en harina de pescado o en carnada para especies mayores, como el atún. Autoridades técnicas en la materia, como el finado biólo. go norteamericano Robert Cushman Murphy, han ser̃alado en términos dramáticos el peligro que se cierne sobre un elemento tan importante de nuestro bioma marino, como es la anchoveta, eslabón básico de nuestra cadena ecológica y del que depende la producción futura del guano y de la harina de pescado en el Perú, y han insistido en la necesidad de adoptar medidas de conservación.

\section{La necesıdad de una acción protectora.}

Ante tal vista del cuadro y con datos e informaciones que diariamente traían más pruebas adicionales de la inmensidad de nuestros recursos marinos, la necesidad de adoptar las medidas pertinentes de salvaguardia se hizo evidente y apremiante.

Al llevar a cabo los estudios necesarios de las medidas requeridas, se reunió material de varias fuentes. La Marina proveyó cartas geo-morfológicas y batimétricas de nuestra costa $y$ del mar adyacente. Entre los estudios ecológicos y biológicos tomados en consideración estuvieron los del profesor Er. win Schweigger, una reconocida autoridad en este campo. En su libro "La Costa del Perú", publicado en 1947, expresó que el límite biológico de la co rriente peruana se encontraba a una distancia de 80-100 millas de la costa en el verano y de 200-250 millas en el invierno. Era un hecho conocido que mientras algunas especies, tales como la anchoveta, se encuentran generalmente cerca de la costa, ellas emigran ocasionalmente - bajo la influencia de varios factores- a 60 ó más millas hacia afuera. Otras especies como el atún $\vee$ el barrilete se encuentran entre las 20 y las 30 millas de la costa; mientras que los cachalotes $v$ las ballenas emigran algunas en la zona norte hasta 100 ó más millas de la costa. Se vio así que en orden a conservar estas especies aprovechables de nuestro complejo marítimo biológi$c o$, era necesario extender una política de control $v$ preservación hasta una distancia de alrededor de 200 millas. Se decidió entonces por el Gobierno de la época, usando el derecho de auto-preservación, tomar la acción necesaria a tal fin.

En atención a todo ello, y como Ministro de Relaciones Exteriores en la época, preparé un proyecto de declaración que someti a la ilustrada consideración del entonces Presidente del Perú, José Luis Bustamante $y$ Rivero, un jurista eminente que más tarde iba a ser elegido Juez de la Corte Internacional de Justicia $y$, subsiguientemente, su Presidente. El proyecto cobró forma, finalmente, en un Decreto Supremo, expedido el 1o. de agosto de 1947, que el Presidente Bustamante firmó y que yo, a mi vez, refrendé. De esta suerte me siento, pues, asociado, desde su origen, con la proclamación que hizo el Perú de un límite de soberanía y jurisdicción mari. timas hasta las 200 millas.

Aparte de las razones geo-morfológicas y socio-económicas mencionadas en el preámbulo del Decreto para ejercer la soberanía sobre el zócalo continental y los recursos pesqueros y otros naturales en los mares adyacentes, el caso de las aves guaneras $y$ las especiales medidas de salvaguardia que requerían, fueron también expresadas en el Decreto. No nos alineamos, pues, con el límite de 200 millas adoptado unas seis semanas antes por Chile, simplemente como una generalización de tal límite, sino en consideración a realidades de nuestro propio caso. Además, tanto para el Perú como para Chile, el concepto del zócalo continental era insuficiente. En algunos puntos no alcanza ni a dos millas de ancho, y sólo en un sector se extiende hasta 60 u $80 \mathrm{mi-}$ llas.

El Decreto, en su parte declarativa, proclamó la soberanía $y$ la jurisdicción nacional sobre el zócalo 
continental y las aguas que lo cubren y -haciendo abstracción de la anchura del zócalo- sobre una área de mar adyacente a la costa hasta una distancia de 200 millas náuticas, en orden a reservar, proteger, mantener y utilizar los recursos naturales $y$ las riquezas de cualquier clase existentes en o debajo de ese mar. El límite de 200 millas quedó sujeto, por lo demás, a alteración "por razón de los nuevos descubrimientos, estudios o intereses nacionales que fueren advertidos en el futuro". Parece obvio que si hubiésemos proclamado soberanía simplemente sobre el zócalo continental y las aguas suprayacentes, habríamos quedado cortos en proteger nuestras pes. querías, que se encontraban en ese tiempo amenazadas. Tampoco habrian quedado ellas suficientemente protegidas por la mera afirmación de un derecho de establecer en una fecha ulterior zonas de conservación en alta mar, a manera de la proclamación de los Estados Unidos.

Finalmente el Decreto establecía, como la proclamación chilena, que el derecho de libre navega ción de naves de todas las naciones dentro de la nueva zona y de acuerdo con el derecho internacional, no era afectado.

Fue generalmente entendido que la jurisdicción exclusiva así proclamada no impediría al Gobierno peruano autorizar a los nacionales de otros países a participar en operaciones pesqueras en la zona, sujetándose a la reglamentación que se expidiera posteriormente.

\section{Efectos de la acción tomada.}

La trascendental acción así adoptada casi simul. táneamente por Chile y Perú, no fue objeto al principic de muchos comentarios, poco preparada como estaba la opinión pública para captar plenamente su alcance $y$ significado. Pero la reacción de afuera no tardó en manifestarse en la forma de reservas oficiales de parte de ciertos poderes marítimos, como el Reino Unido y los Estados Unidos. Consideraban que nuestras reivindicaciones eran contrarias al derecho internacional. Luego de nuestras respuestas con argumentos de apoyo, empezó un debate general que ha durado ya por 25 años. De este debate, lo que al principio pudo haber sido sólo una tesis, puede decirse que ha emergido una doctrina. $Y$ esta doctrina no ha cesado de ganar terreno en el derecho internacional del mar.
Creo oportuno decir aquí que el límite de las 200 millas nunca se declaró con un sentido de aplicación universal. Se justificaba en países como Perú y Chile, con inmensos espacios oceánicos frente a sus costas, prácticamente no tocados por actividades pesqueras foráneas, con problemas socio-económicos para los cuales los recursos marítimos ofrecían una solución. Sin perder de vista que el derecho internacional es en principio uno $y$ uniforme, que siempre ha buscado formular reglas generales aplicables a to. dos los Estados, seguimos creyendo que es posible, sin renunciar a esta idea, considerar la elaboración de reglas tales que puedan ser adaptadas a la particular situación de ciertos Estados.

Teniendo en mente esta idea, trataré de referir. me, en sus lineamientos generales, a los sucesos más significativos en la consolidación de la doctrina de las 200 millas.

\section{Desarrollo de la reivindicación de las 200 millas.}

Dos repúblicas Centroamericanas fueron las primeras en asociarse al límite de las 200 millas: Costa Rica en 1948 y El Salvador en 1950, la última incorporando el principio en su Constitución, como aguas territoriales. Guatemala (1949) y Nicaragua (1948-1950) y el Brasil también declararon al zócalo continental como parte del territorio nacional. Gran Bretaña, el más consistente adversario a innovaciones en estas materias, pasó "Orders in Council", entre los años 1948 y 1950, incorporando a sus posesiones en el hemisferio americano (Honduras Británica, Bahamas, Jamaica y las islas Falkland) el área del zócalo continental que se encuentra debajo del mar contiguo a las costas de estas posesiones.

En 1952, Chile, Perú y Ecuador por la ya mencionada "Declaración de Santiago" establecieron el innovación de este documento fue que el límite de las 200 millas quedó fijado $y$, en realidad, se señaló como una distancia mínima; y la expresión "libre navegación" usada en las declaraciones originarias de Chile y del Perú, se cambió por la de "pasaje inocente".

En el mismo ámbito latinoamericano se llevaron a cabo varias reuniones, pudiendo señalarse como el más importante desarrollo a los llamados "Principios de México" (1956) en los que se enunció-como una expresión de la conciencia jurídica del hemisfe- 
rio- que cada Estado puede establecer dentro de límites razonables, la extensión de sus aguas territoria. les.

En el año de la "Declaración de Santiago" (1952) una expedición ballenera francesa se aventuró cerca de nuestras costas y obtuvo una abundante captura. La impunidad con que se llevó a cabo esta primera expedición, cuando el patrullaje era deficiente, fue contrarrestada por la captura, en 1954, de la mayor parte de la expedición ballenera organizada como un desafío a la proclamación peruana, por el naviero griego Onassis. La publicidad mundial que se dió a este incidente, que terminó con lá liberación de los barcos capturados después del pago de una multa de tres millones de dólares, hizo ver claro a quienquiera que pudiera haber estado pensando en transponer nuestra soberanía pesquera, que el Perú actuaría firmemente con los transgresores. Hacia esta época hubo también una protesta británica motivada por el hecho de que Onassis se habia asegurado en el Lloyds de Londres contra el riesgo de captura de sus barcos. Fue así como Lloyds pa. gó la multa, pero nunca reclamó de ese pago.

Reglamentaciones para el otorgamiento de permisos y licencias habian sido entretanto, adoptadas por Perú, Chile y Ecuador, para barcos de bandera extranjera que pescaran en sus respectivas aguas. Desde luego, estos permisos incluían el pago de ciertos derechos $y$, en el caso del Perú, excluían a especies como la anchoveta cuya captura quedaba reservada a los nacionales. Algunos de los tuna clippers de California se proveyeron de los permisos respectivos, pero otros que no lo hicieron fueron capturados por patrulleros peruanos o ecuatorianos y llevados a puerto donde fueron multados. El pago se hizo bajo protesta $y$ dio lugar a incidentes diplomáticos con los Estados Unidos.

La progresión de los derechos de los Estados costeros se extendió, entretanto a otros continentes. Por actos unilaterales dirigidos ya fuera a la utilización de las pesquerías, como en el caso de Islandia - de la República de Corea, o hacia la utilización de los depósitos de petróleo en el zócalo continen. tal como en los casos de Filipinas, Australia, Pakistán, Irán, también Islandia y un número cada vez mayor de Estados y emiratos del Medio Oriente y del Golfo Pérsico. No menos de 30 territorios independientes habían tomado acción de tal suerte hacia el año 1955.
Mientras tanto, continuaba el trabajo de la Comisión de Derecho Internacional de las Naciones Unidas en la codificación del Derecho del Mar. Fue discutida una proposición para conceder al Estado costero del derecho de imponer medidas de conservación marítima de los recursos en una zona adyacente a sus aguas territoriales hasta un límite de 200 millas náuticas, pero la idea quedó abandonada.

Por otra parte, en la Asamblea General de las Naciones Unidas de 1956, anterior a la primera Conferencia Mundial sobre el Derecho del Mar, los tres países del Pacífico - Sur -Chile, Ecuador y Perú- explicaron su posición con respecto a las 200 millas. Los tres dijeron, en ese entonces, que no habian reclamado aguas territoriales hasta tal distancia, sino una zona especial para la conservación $y$ utilización de las pesquerías y otros recursos existentes en dicha zona.

\section{Primera Conferencia sobre el Derecho del Mar.}

Vino luego la primera Conferencia sobre el Derecho del Mar, en 1958. Los tres países del Pacífico Sur explicaron entonces, ante un foro internacional especializado, las bases y fundamentos de su posi ción. Al mismo tiempo objetaron las innovaciones extremadamente limitadas contenidas en el proyecto de la Comisión que sirvió de base para las discusiones y que lo más que reconocían al Estado ribereño era el papel de un socio minoritario en el gobierno de las pesquerías en alta mar más allá de sus aguas territoriales, las que no deberían exceder, según la Comisión, de 12 millas. Hubo, con todo, una reacción positiva $y$ alentadora hacia nuestras reivindica. ciones de parte de un buen número de delegados de paises en desarrollo,-pero no en la medida suficiente para nuestra posición, todavía no lo suficientemente conocida o expuesta como para ser reconocida o incorporada como una nueva regla del Derecho del Mar. Para los delegados de las grandes potencias, adictas a los llamados principios tradicionales, éra mos poco más que heréticos. Observaciones sarcásticas se nos hicieron. Uno de los delegados me preguntó ¿por qué 200 millas $y$ no 500? Me tocó contestar a ésto informándolo de las bases técnicas $y$ científicas en que nos habiamos basado para adoptar aquella distancia.

Como es sabido, no se llegó a un acuerdo en la 
Conferencia de 1958 en cuanto al límite del mar territorial y otros asuntos relacionados con la mate. ria. Sin embargo, sí se obtuvo una mayoría de dos tercios para la adopción de cuatro Convenciones: sobre mar territorial y la zona contigua, sobre la alta mar, sobre pesca y conservación de los recursos vivos de la alta mar, y sobre la plataforma continental. Aunque ninguna de estas Convenciones satisfacía los derechos proclamados hasta el límite de $200 \mathrm{mi}$. llas, un tímido avance se logró con el reconocimien to de los derechos especiales de los Estados coste ros, inherentes a su posición geográfica en materias relacionadas con las pesquerias.

Después de ésto, Perú, Chile y Ecuador consideraron necesario hacer una declaración conjunta, en la que dejaron establecido que los resultados de la Conferencia demuestran el reconocimiento creciente del derecho especial del Estado costero inherente a su posición geográfica y una amplia medida de apo. yo a nuestras reivindicaciones. A la vez hicieron constar su intención de mantener en plena vigencia el sistema regional maritimo del Pacifico Sur, hasta que soluciones justas y humanas fuesen encontradas.

\section{Segunda Conferencia.}

Como un corolario de la primera Conferencia, ta Asamblea General de las Naciones Unidas convocó a la Segunda Conferencia del Derecho del Mar, en Ginebra, en 1960, para considerar mayormente las cuestiones del mar territorial y el límite de las pesquerías. Ochentiocho Estados estuvieron representados en esta Conferencia, dos más que en la primera. Careció también esta segunda Conferencia de la suficiente preparación científica y técnica para considerar las situaciones especiales de ciertos Estados costeros. Otra vez abogamos por nuestro caso y presentamos un proyecto de resolución que reconocía, en casos excepcionales, al Estado ribereño, el derecho de explotar los recursos pesqueros del mar frente a sus costas. Mantuvimos que tal derecho del Estado ribereño a los recursos de su mar adyacente, era inherente a su posición geográfica $y$, por lo tanto, pre-existente a cualquier reivindicación hecha ante la comunidad internacional; que fue por virtud del principio geográfico de la contiguidad que en la Conferencia de 1958 se reconoció la soberanía del Estado costero sobre la plataforma continental, un reconocimiento éste que benefició a los diferentes Estados de una manera muy desigual. Por ejemplo, en ningún otro respecto había esta situación de beneficio y privilegio sido más aparente que para los seis países que bordean el Mar del Norte, todo el cual es zócalo continental.

La Segunda Conferencia tampoco llegó a adoptar con la necesaria mayoría de los dos tercios, la propuesta para un límite de seis millas de mar territorial, más otras seis millas adicionales de zona pes. quera exclusiva. Este adverso resultado, interpretado como una consolidación adicional para el límite de las doscientas millas, llevó al jefe de la delegación peruana, Profesor Ulloa, a emitir una declaración, que se incluyó entre los documentos de la Conferencia, en la que expresó que el reconocimiento por varias delegaciones de la situación especial de ciertos Estados costeros, haría una profunda impresión en el derecho internacional contemporáneo respecto del mar y conduciría a un decisivo paso adelante en el desarrollo de ese derecho.

\section{Desarrollos subsiguientes a la Segunda Conferencia Mundial.}

El fracaso de este segundo intento de las Naciones Unidas para resolver las cuestiones pendientes, puede haber estimulado a otros Estados a expandir, sin más, sus derechos marítimos. Me referiré brevemente a tales acciones en los varios continentes.

\section{Europa}

Por más obvio que pueda ser el mencionarla ante este ilustrado auditorio, debo referirme a la Convención Europea de Pesquerías firmada en Londres en 1964 por trece gobiernos, incluyendo al Reino Unido. Provee esta Convención el reconocimiento de una zona de pesquería exclusiva de seis millas $y$, además, que "dentro de la faja situada entre las seis y las doce millas, desde la línea de base del mar territorial, el derecho a pescar será ejercido sólo por el Estado costero y por las demás partes contratantes cuyos barcos pesqueros hayan pescado habitualmente en esa faja entre el 10 . de enero de 1953 y el 31 de diciembre de 1962". Esto es todo un apartamiento de la posición que los países signatarios mantuvieron cuando la Conferencia en Ginebra en 1960 llegó a su término. A este respecto también debo hacer referencia al caso de islandia, que como todos lo sabemos, extendió sus 
límites pesqueros a 50 millas náuticas, a partir de 10. de setiembre de 1972. Las razones dadas para esta extensión fueron primordialmente dos: la urgente necesidad de conservar el stock de peces que en las aguas de Islandia estaba en peligro inminente de agotamiento, y las necesidades económicas de la población de Islandia que depende casi exclusivamente de las pesquerías costeras para su supervivencia. Conozco, desde luego, las objeciones que presentaron Gran Bretaña y la República Federal de Alemania a este respecto. Aún cuando seamos buenos amigos de Gran Bretaña, no podemos dejar de simpatizar a la vez con el dramático caso de la pequeña Islandia $y$, debería agregar, icon su modesta reivindicación comparada con la nuestra!. Algunos islandeses consideran que sus reivindicaciones no han ido lo bastante lejos $y$ se acogen en su defensa a nuestros argumentos, por lo que nos sentimos algo así como socios que luchan por una causa común.

\section{América del Norte.}

La tendencia a extender los límites marinos al canzó también a los Estados Unidos de América y al Canadá. Los Estados Unidos, sin especificar los límites de su mar territorial, extendieron sus límites pesqueros en 1966 hasta las 12 millas. Más recientemente, en un documento común circulado por Estados Unidos $y$ la U.R.S.S en el que consultaban con otros países respecto de la próxima Conferencia Internacional sobre el Derecho del Mar, sugirieron un límite de 12 millas para el mar territorial. También es significativo que la legislatura del Estado de Massachusetts aprobase en 1969 un acuerdo en el que se recomienda al Congreso federal la adopción de un límite de 200 millas para la pesca en la costa Atlántica, a fin de evitar la pesca indiscriminada de ciertas especies que vienen haciendo flotas ex tranjeras, con riesgo de agotarlas. En la Cámara fe deral de Representantes, 25 de sus miembros presentaron recientemente un proyecto de ley que incor. pora esta recomendación de Massachusetts, iNo ca. be, pues, duda que la cifra de 200 millas ejerce ur cierto hechizo y continúa ganando amigos!

El Canadá en 1970, extendió a su vez su juris dicción pesquera hasta 100 millas en el archipiélagu ártico. Al mismo tiempo estableció límites de pesci cerrados frente a ciertas zonas, en las que consideró necesario reservar los'recursos para sus nacionales.

\section{Africa}

Desde 1963 los nuevos Estados africanos entraron también en la contienda. Siete de ellos han pro. clamado de algún modo la jurisdicción nacional más allá de las 12 millas. Ghana estableció así, en 1963, el límite de 100 millas como una zona de conservación pesquera y el 28 de marzo del presente año de 1973 anunció la extensión de sus aguas territoriales de 12 a 30 millas náuticas. Por otro decreto de la misma fecha se dijo que el Gobierno podia declarar la distancia de 100 millas náuticas a partir del límite exterior de las aguas territoriales como uria zona de conservación pesquera. Guinea, en 1964, extendió el límite de su mar territorial a 130 millas. En el Camerún la Asamblea Nacional autorizó en 1967 la extensión de su mar territorial a otras 18 millas. Senegal, a su vez, estableció en 1968 una zona exclusiva pesquera de 18 millas. Dahomey, en el mismo año, extendió su soberanía respecto del subsuelo y el zócalo continental hasta 100 millas de la costa. Gabon en 1970, fijó sus aguas territoriales en 25 millas. Y Sierra Leone estableció su límite en 200 millas, convirtiéndose asi en el primer país africano que se ha alineado con la distancia latinoamericana. Kenya, aún cuando no ha adoptado este límite, lo está considerando, desde que en la reunión de Agosto de 1972 en Ginebra del Comité de las Naciones Unidas sobre el lecho submarino, formuló un proyecto de articulado en el que se propone la jurisdicción económica exclusiva hasta las 200 millas, incluyendo las pesquerías y 12 millas de mar territorial (UN Doc. A/AC 138 SC 1'/1.10.).

A esta lista de países africanos debiera ahora agregarse el caso de Marruecos. Por un Decreto del presente año de 1973, ha sido declarado un mar territorial de 70 millas en las costas del mar Mediterráneo y del Océano Atlántico. En reciente reunión en Nueva York del Comité preparatorio de la III Conferencia de las N.U., la delegación marroquí habló, sin embargo, de "derechos exclusivos de pesca" como propósito del Decreto.

Esta variación en los límites y en su naturaleza jurídica demuestra que los Estados africanos han procedido independientemente en la expresión de un común deseo. En orden a establecer una coordinación, se han realizado importantes reuniones como la del Comité Consultivo Afro-Asiático en Codombo (Sri Lanka) en 1971 y en Lagos (Nigeria) en Enero de 1972; y el Consejo Científico para Africa en Ibadan, Nigeria, en Noviembre de 1971. 
Asia

Seis países asiáticos han extendido sus límites jurisdiccionales marítimos más allá de las 12 millas. La República de Corea en 1952 estableció una zona exclusiva de pesca de 20 a 200 millas. La India en 1956, Ceylan (ahora Sri Lanka) en 1957 y Pakistán en 1966 fijaron zonas pesqueras de conservación de 100 millas más allá del límite de sus aguas territoriales. Pakistán nuevamente, después de su separación de Bangladesh, por una ley fechada el 23 de marzo de 1973 fijó en 12 millas el límite de sus aguas territoriales en el Mar de Arabia, más $60 \mathrm{mi}$ llas de una zona exclusiva de pesca. Por otra parte, Filipinas e Indonesia han adoptado el concepto del archipiélago, en el que sus aguas territoriales se extienden entre las líneas de base de las islas más distantes para constituir una unidad que difícilmente puede ser impugnada. Por su parte, la República Popular China, sin haber extendido sus propios límites marítimos, $y$ desde que estableció relaciones diplomáticas con el Perú y otros países latinoamericanos, ha expresado varias veces su apoyo a la reivindicación de las 200 millas.

\section{Australasia.}

Australia y Nueva Zelandia, que han estado si. guiendo todos estos desarrollos con mucha atención, especialmente los de América Latina, han iniciado a su vez una campaña. En un documento conjunto de trabajo circulado en 1972 en el Comité del lecho submarino, consideran al Estado costero como titular de una jurisdicción exclusiva respecto de los recursos vivos del mar en una zona adecuada, por su anchura, de la alta mar adyacente a sus aguas territoriales. Esta zona de pesquería, de acuerdo a una declaración de Nueva Zelandia ante el Comité "puede formar parte de una zona económica general". Tan cauto esquema acaba de ser precisado por los dos países en una nueva declaración conjunta hecha en Nueva York el 9 de marzo de 1973 ante el Comité preparatorio de la III Conferencia, en el sentido de que la nueva Convención sobre la materia debiera considerar derechos exclusivos de pesca hasta 200 millas para los Estados costeros. Este es, en verdad, un gran apoyo a nuestra causa.

\section{Nuevas proclamaciones de 200 millas $y$ otros desarrollos en América Latina.}

De la América Latina puede decirse que la extensión de los derechos del Estado costero ha continuado un curso progresivo $y$ hasta triunfal $y$ que $e$ límite de las 200 millas está, de algún modo, gene ralizado. A las proclamaciones originarias de Perú y Chile en 1947, siguieron, en efecto, las de Costa Rica (1948) y El Salvador (1950). Vino luego la Declaración de Santiago (1952) que suscribieron Chile, Ecuador y Perú. Siguieron las de Nicaragua (1965), Argentina (1966), Panamá (1967), Uruguay (1969) y Brasil en 1970. Nicaragua hizo su proclamación como la de una zona pesquera. Todos los otros países que siguieron a los tres del Pacífico Sur, como mar territorial, respecto del cual reclaman soberanía y jurisdicción.

En cuanto a las proclamaciones de Argentina $y$ Uruguay, tienen ciertos aspectos particulares que importa señalar. Dentro de las 200 millas de mar territorial reconocen una primera zona hasta las $12 \mathrm{mi}$ llas con todas las competencias y prerrogativas del mar territorial, tales como pasaje inocente $y$ derecho de pesca reservado, en principio por lo menos, a los nacionales; $y$ una segunda zona entre las 12 y las 200 millas, con libertad de navegación y sobrevuelo y la posibilidad de autorizar a «barcos pesqueros de bandera extranjera, de acuerdo con las reglamentaciones del Estado costero. Pero ninguna proclama. ción ha sido más radical que la del Brasil, que venía objetando nuestra posición tan obstinadamente. Ahora sus 200 millas son mar territorial en toda su extensión, sin ninguna concesión respecto a la nave gación o al sobrevuelo.

De esta suerte, el límite marítimo de las 200 millas se extiende ahora, ininterrumpido, a lo largo del litoral de seis países: Ecuador, Perú, Chile, Argentina, Uruguay y Brasil, cubriendo el $78.8 \%$ de las costas del subcontinente. $Y$ a ésto debe agregarse la proclamación de Francia en favor de la Guayana Francesa, de un límite exclusivo de pesca de 80 millas.

\section{Reuniones Latinoamericanas.}

Con el fin de coordinar posiciones ante la próxima conferencia del derecho del mar $y$ de encontrar comunes denominadores para una acción prácti. ca, importantes reuniones se realizaron en Montevideo (Uruguay) y en Lima (Perú) en 1970; otra, de los países del Caribe, tuvo lugar en Santo Domingo en 1972. De estas reuniones han emanado importan. tes documentos con declaraciones de principios. In 
tensa actividad diplomática continúa para clarificar $y$ fijar ideas en orden a presentar un frente unido $y$ ganar nuevos aliados.

\section{Declaración de Nlontevideo sobre derecho del mar (mayo 1970).}

A iniciativa del Uruguay los nueve paises del llamado "Club de las 200 millas" se reunieron en Montevideo en Mayo de 1970 y suscribieron al cabo, el 8 de ese mes, un documento al que se denominó "Declaración de Montevideo sobre Derecho del Mar" en el que, sin aludir específicamente a la distancia de 200 millas, se recogió y desarrolló la fundamentación de la "Declaración de Santiago" de 1952, reconociendo "la existencia de un nexo geográfico, económico y social entre el mar, la tierra y el hombre que la habita del que resulta una legítima prioridad en favor de las poblaciones ribereñas para el aprovechamiento de los recursos naturales que les ofrece su ambiente marítimo". En la parte declarativa del instrumento, que enuncia seis principios básicos del derecho del mar, se establece en el primero, "el derecho de los Estados ribereños a disponer de los recursos naturales del mar adyacente a sus costas, y del suelo y sub-suelo del mismo mar, para promover el máximo desarrollo de sus econo mías y elevar los niveles de vida de sus pueblos".

\section{Declaración de los Estados Latinoamericanos sobre e) Derecho del Mar (Lima, 8 Agosto de 1970)}

Continuando con la politica de contactos para ganar adeptos $v$ alinear posiciones, todos los países latinoamericanos fueron invitados a reunirse en Lima en Agosto de 1970, en una cita que tuve el honor de presidir. Diecinueve países concurrieron a la invitación $y$ algunos observadores, entre ellos uno de Islandia y otros de Africa. En la declaración de principios comunes que fue entonces firmada, después de repetir el primer preámbulo de la declaración de Montevideo, se agrega que como consecuencia de la relación preeminente entre el mar, la tierra $\checkmark$ el hombre que la habita, ha sido reconocido el derecho de los Estados ribereños a establecer los alcances de su soberanía o jurisdicción marítimas de acuerdo con criterios razonables, atendiendo a sus realidades geográficas, geológicas y biológicas, y a sus necesidades y responsabilidades socio-económicas; $y$ en su parte declarativa reafirma, en términos similares a los de la Declaración de Montevideo, "el derecho inherente del Estado ribereño a explorar, conservar $v$ explotar los recursos naturales del mar adyacente a sus costas, $y$ del suelo y subsuelo del mismo mar, asi como d: la plataforma continenta y su subsuelo, para promover el máximo desarrolk de sus economias y elevar los niveles de vida de sus pueblos".

Aunque el límite de las 200 millas fue el prin. cipal factor de la reunión de Lima, no se hace men. ción a él en la Declaración, desde que no todos los países que acudieron a la cita lo tenían adoptado. Como en Montevideo, hubo algunas exposiciones razonadas de los votos, para clarificar cuestiones relativas a la libre navegación $y$ al pase inocente. Pero las bases económicas que justifican la extensión de los derechos del Estado ribereño permanecieron firmes, esto es: las necesidades de subsistencia y desarrollo del pueblo que habita el territorio, $y$ el vínculo o relación que existe entre el mar, la tierra $y$ sus habitantes.

\section{Declaración de Santo Domingo (Junio de 1972)}

A continuación quince de las repúblicas ribere. ñas del área del mar Caribe, entre ellas Colombia, Venezuela, Panamá, Costa Rica, Guatemala, Haití, México, Santo Domingo y Honduras, con sus pro. blemas geográficos propios e instadas por Colombia que deseaba consolidar su punto de vista ya expresado, se reunieron en Santo Domingo en Junio de 1972 para considerar las recientes tendencias sobre el derecho del mar $y$ buscar una política común que tomara en consideración las distintas posiciones geográficas que no permitían, en todos los casos, un limite hasta las 200 millas. Los resultados de la reunión fueron expresados en la Declaración de Santo Domingo, aprobada el 7 de Junio por todos los participantes excepto, por una parte, El Salvador y Panamá, desde que ya estos dos paises habian adoptado el límite de 200 millas, y por otra Barbados, Guayana y Jamaica los que, por razones temporales, como miembros de la Comunidad Británica, no se habían todavia asociado al "Club". Sin embargo, expresaron sus simpatías con los resultados de la reunión y El Salvador que sin ser ribereño del Caribe, insinuó la posibilidad de asociarse también a la Declaración.

La Declaración de Santo Domingo cubre los principales aspectos del Derecho del Mar. La adopción de un límite de 12 millas para las aguas territoriales, más una zona adyacente económica llamada "mar patrimonial" con derechos de soberania sobre sus recursos naturales, fue enunciada. Se recomendó que la extensión del "mar patrimonial" fuera fijada por acuerdos internacionales, preferiblemente mundiales, y que la suma de esta zona con el mar terri. 
torial, teniendo en cuentá las circunstancias geográficas de cada caso, no debería exceder de las 200 millas náuticas, con libre navegación y sobrevuelo. Se pensó que limitando el derecho de paso inocente a una zona inmediata de 12 millas, se evitaría una de las mayores objeciones al límite de 200 millas, cuando éste es asimilado al mar territorial.

La Declaración de Santo Domingo es expresión de un espiritu de compromiso, en orden a ganar la posición de los países latinoamericanos. Mantiene la institución del mar territorial, pero promueve a la vez, el derecho del Estado costero a un posible límite de 200 millas, según las circunstancias geográficas $y$ mediante acuerdo internacional.

Quiérase o no, hay que reconocer a la luz de estas sucesivas declaraciones que existe avenimiento respecto a las 200 millas, sus bases económicas y la necesidad de estar en conformidad con la evolución del derecho del mar. Después de esta Declaración bien puede pues decirse que el limite de las 200 millas es hoy proclamado o apoyado por todos los paises latinoamericanos.

\section{Dictamen del Comité Jurídico Interamericano 19 de febrero de 1973).}

El siguiente acontecimiento de significación fue el dictamen del Comité Jurídico Interamericano. Es éste el órgano consultivo de la OEA para las cuestiones legales, compuesto de 11 miembros a título personal. Después de una serie de debates que empezaron en 1971, nueve de los miembros presentes firmaron en Río de Janeiro el 9 de febrero de 1973, una recomendación que nuevamente sanciona el limite de 200 millas en los siguientes términos: "La soberanía o jurisdicción del Estado ribereño se prolonga más allá de su territorio $y$ de sus aguas interiores, a una extensión de mar adyacente a sus costas hasta un máximo de 200 millas náuticas, así como al espacio aéreo, al lecho y al subsuelo de ese mar. De consiguiente, es valida la fijación de hasta 200 millas que haya hecho o pueda hacer cualquier Estado americano, siempre que se respete lo dispuesto en el artículo 4". "4. Dentro de los límites de la zona adyacente y a partir de la distancia de 12 millas, las naves y aeronaves decualquier Estado, con litoral marítimo o sin él, gozan del derecho de libre navegación y sobrevuelo, sujeto a las reglamentaciones pertinentes del Estado ribereño relativas a la preservación del medio marino, a las actividades de exploración, explotación e investigación científica que se realicen en él, y a las seguridades para la navegación $y$ el transporte muritimo, $y$ todo ello de acuerdo con el Derecho Internacional". Es este, sin duda, el texto más equilibrado y más cuidadosamente redactado que haya emanado de un cuerpo interamericano facultado para reunir diferentes posiciones. Es también el que se ha puesto más al dia, como que toma en cuenta el nuevo problema de la polución oceánica. Sin duda ejercerá influencia en las futuras reuniones preparatorias de la Conferencia mundial y quizás allane el camino a la unificación de posiciones, especialmente con los Estados Unidos. Es cierto que el miembro norteamericano del Comité, Profesor William Barnes de Harvard, firmó el dictamen con algunas reservas, como lo hicieron también otros miembros del Comité al explicar sus votos.

Papel de las Naciones Unidas en recientes desarrollos sobre el Derecho del Niar.

En vista de este $y$ otros desarrollos que han venido cobrando forma desde la segunda Conferencia de Ginebra (1960), se comprenderá que la Organización de las Naciones Unidas se haya hecho car. go del problema. Fue en 1967, como resultado de una propuesta de Malta, que la Asamblea General adoptó la Resolución No. 2340 (XXII) sobre la utilización pacífica de las profundidades oceánicas "más allá de los límites de la jurisdicción nacional". Una Comisión especial fue entonces establecida para buscar solución al problema y una serie de resoluciones subsiguientes de la Asamblea General completaron la idea, aludiendo al hecho de que la noción de altamar no da una guía suficiente al respecto; que los recursos existentes en las profundidades oceánicas son herencia común de la humanidad; y que las actividades de exploración y explotación en esta inmensa región debieran ser reguladas por el derecho internacional que se establezca. Se vio pronto, en el curso de los trabajos de la Comisión Especial, que el asunto concernía a los límites de la jurisdicción nacional, "límites que están aún por definirse" y, así mismo, a la cuestión de la extensión del zócalo continental. De allí nació la idea de convocar a una nueva Conferencia sobre el Derecho del Mar, con facultad de pronunciarse sobre todos los problemas pendientes, tanto los que atañen a los desarrollos ocurridos desde 1960, cuanto a la cuestión de las profundidades oceánicas. Se juzgó también que los problemas relativos al espacio oceánico están íntimamente interrelacionados y debieran se। considerados como un conjunto. Fue por este motivo que se adoptó la Resolución $2750 \mathrm{C}(\mathrm{XXV})$ el 17 de diciembre de 1970, que convoca a una Con. 
ferencia sobre el Derecino del Mar en 1973. Por otra resolución de la Asamblea General de la misma fecha se hizo una declaración de principios para regla. mentar el uso de las profundidades oceánicas y su subsuelo, más allá de los límites de la jurisdicción nacional. En lo que se refiere al Comité Especial, el número de sus miembros fue luego aumentado $y$ ha venido actuando en la práctica dicho Comité como el preparatorio de la Conferencia. La convocatoria de ésta fue confirmada por la Resolución de la Asamblea General 3029 de diciembre de 1972, que llama a una Sesión preliminar de la Conferencia en Noviembre/Diciembre 1973, en Nueva York, para discutir las cuestiones de organización.

\section{Esclarecimiento de cargos y recapitulación de princi- pios.}

Después de esta visión panorámica -necesariamente breve- de la tesis de las 200 millas y de su progresión con respecto al derecho del mar, creo que debo tratar de sintetizar los principios básicos de nuestra posición y descartar el cargo que se nos hace de que hemos asumido una actitud contraria al derecho internacional. Trataré en primer término del carácter unilateral de las medidas adoptadas.

\section{El carácter unilateral de las medidas}

Como lo he indicado anteriormente, fue la ausencia de reglas internacionales que gobernaran la utilización del mar como fuente de riqueza la que originó las medidas de auto-defensa por los Estados interesados. En un Memorandum del Secretario General de las Naciones Unidas publicado en 1949, antes de la primera Conferencia sobre el derecho del mar, se dijo que la acción de los Estados que habian adoptado tales medidas era inobjetable desde el ángulo de la justicia y la equidad, desde que el conflicto de intereses había hasta entonces frustrado los intentos de codificación $y$ hecho más difícil en este campo que en ningún otro del derecho internacional la adopción de normas que pudieran ser aceptadas por todas las naciones. (Survey of International Law UN doc. A/CN. 4/1/Rev. 1, 10 febrero 1949 , p. 41). Siguiendo esta línea de pensamiento, el Profesor Philip Jessup, en su comentario a un opúsculo que escribí sobre el tema, declaró en 1955 que "en esencia la reclamación peruana se basa en el más firme terreno posible, a saber: el interés nacional en la conservación de los recursos naturales del mar adyacente y del lecho submarino agregado a una derecho general de auto-preservación". (The
American Journal of International Law, Vol. 49, No. 4 - Oct.-Dec., 1955, p. 593).

Es menester señalar que las objeciones al carácter unilateral de las medidas, provienen principalmente de países que no han titubeado en adoptar tal género de limitaciones respecto de la alta mar, cuando las creyeron necesarias, para proteger un interés particular. ¿Qué otra cosa son las competencias especiales ejercidas por varios Estados más allá de sus aguas territoriales, cuando se trataba de la apropiación de bancos de peces sedentarios o de protección de intereses fiscales, aduaneros, sanitarios o de policía? ¿Qué otra cosa son acciones como la proclamación del Presidente Roosevelt, poco después del estallido de la segunda guerra mundial, prohibiendo actos de beligerancia en una zona, patrullada desde ese día, de 200 millas desde las costas de los Estados Unidos, y las Ilamadas "zonas de peligro" establecidas alrededor de las islas del Pacífico cuan do se realizaron explosiones nucleares experimenta les?

Demuestra ésto que en ninguna otra rama del derecho internacional las acciones unilaterales encuentran más favor que en el derecho del mar. La misma Corte Internacional de Justicia, en su fallo ya histórico de 1951 en el caso Anglo-Noruego, dió sanción a la validez de la determinación unilateral de los limites del mar territorial, aún cuando reconociendo que estos límites tienen un aspecto internacional.

La única conclusión lógica a que llevan estos hechos pertinentes es que no existe un derecho internacional que impida que los Estados costeros establezcan los límites que necesitan, siempre que no infrinjan los límites de otro Estado vecino.

\section{La cuestión de la naturaleza jurídica del límite de las 200 millas.}

Desde las proclamaciones por el Perú y Chile en 1947 sobre el límite de las 200 millas y posteriormente, después de la Declaración de Santiago de 1952 y de varias conferencias internacionales, la cuestión de la naturaleza jurídica de esta zona ha sido interpretada de varias maneras, esto es, si se trata de un mar territorial con todas las prerrogativas que ello implica, o de un nuevo concepto, de una zona sui generis, en la que la soberanía puede ser ejercitada respecto de la conservación y exclusiva utilización de los recursos marinos. Al principio fue generalmente entendido que este último era el. caso $y$ el mismo criterio fue expresado por los tres pro- 
tagonistas del nuevo concepto en las dos Conferenclas en 1958 y 1960, porque ni en la proclamación peruana ni en la chilena, ni en la Declaración de Santiago, fue usada la sacrosanta expresión "mar territorial". Sin embargo, mientras en las declaraciones de Chile: y del Perú se dijo que ellas no afectaban el derechio de libre navegación de naves de todas las naciones, en la Declaración tripartita de Santiago expuso que ella no afectará el paso inocente.

De la alusión a "paso inocente e inofensivo" a través de la zona marítima señalada, para las naves de todas las naciones, que generalmente es usada con referencia al mar territorial, asi como de otras expresiones en actos de derecho positivo, tales como las de "dominio marítimo de la Nación", que se encuentra en el Decreto peruano, algunos comentaristas no tardaron en inferir que lo que se había en realidad proclamado era un mar territorial de 200 millas, y desde ese entonces han tratado de mantener su punto de vista. Chile, por su parte, nunca ha participado de tal opinión y continuó diciendo que sus aguas territoriales tienen sólo tres millas, una posición comprendible para el país más austral del planeta, obviamente interesado en que el mar libre $y$ las comunicaciones aéreas permanezcan lo menos restringidas que sea posible. Ecuador, sin embargo, creyó conveniente a sus intereses $y$, como una mejor defensa contra las incursiones de barcos pesqueros foráneos, modificar en 1966 su Código Civil y establecer su límite de 200 millas como mar territorial.

En el Perú, en el lenguaje corriente y en el de la prensa, la zona de las 200 millas suele ser mencionada como "mar territorial". En ciertas leyes especiales promulgadas desde 1952 está implícito que dicha zona es parte del dominio nacional, y en la ley sobre aviación civil se dice que el Perú ejerce soberanía exclusiva sobre el espacio aéreo encima "de las aguas jurisdiccionales" hasta una distancia de 200 millas. Solamente en una ley interna especial, el límite de las 200 millas está incidentalmente mencionado como mar territorial. Pero en ningún acto de derecho positivo público se ha declarado inequívocamente que el mar territorial del Perú se extienda hasta las 200 millas. En los foros internacionales los delegados peruanos al sostener nuestra posición se han abstenido de identificar el límite de las 200 millas con la idea de "mar territorial".

Esta indefinición, que puede ser necesario resolver pronto, se explica por el tiempo en que nuestra proclamación fue hecha (1947). De esta suerte los gobiernos del Perú, Chile y Ecuador, de acuerdo con sus objetivos y conscientes de participar en la formulación de nuevas normas, se cuidaron de iden. tificar los derechos proclamados - por lo menos hasta después de las conferencias de Ginebra- con la clásica institución del mar territorial, por cuanto esta noción era inadecuada y parecía inconveniente para expresar la naturaleza $v$ expresión de una soberania y jurisdicción exclusivas relativas a la protección y utilización de los recursos marinos hasta una distancia de 200 millas. De allí que la opinión prevaleciente fuera la de que lo que se había establecido era una institución sui-generis.

\section{El concepto de Soberanía.}

Parecería que el uso genérico de la expresión "soberanía y jurisdicción exclusivas" ha hecho más fácil a un número creciente de países cuyas posiciones originales fueron opuestas a la idea de extender sus derechos nacionales hasta tal distancia, el apoyar la zona de 200 millas, y la han adoptado ahora o se proponen adoptarla como el más razonable límite, aunque no como mar territorial. Esta es la fórmula propuesta por Kenya y los paises del Caribe $y$ más recientemente por Australia y Nueva Zelandia.

También se ha dicho por los territorialistas que el término soberanía usado en nuestras proclamaciones no admite calificación y que sólo puede entenderse en un sentido absoluto, el que corresponde al mar territorial. Pero aparte del hecho de que, aún tratándose de aguas territoriales existen conceptos $\mathrm{li}$. mitativos tales como el paso inocente, los que acuden al mencionado argumento pierden de vista algo más, como dijera el profesor noruego Raestad hace más de 50 años: "que la soberanía marítima de un Estado no se verá en lo menor disminuida por la más completa diferenciación que se haga de los derechos que componen el concepto de soberanía" (A. Raestad, La Mer Territoriale, Paris, Pedone, 1917, p. 185). La Comisión de Derecho Internacional de las Naciones Unidas $y$ más tarde la Conferencia de 1958, parecieron compartir esta opinión cuando, al redactar la Convención sobre la Plataforma Continental, reconocieron al Estado costero sólo parte de los derechos $y$ prerrogativas que corresponden al concepto de soberanía, al atribuir al Estado ribereño derechos soberanos sobre el zócalo continental sólo para fines particulares: los de exploración y explotación de sus recursos (Convención sobre la Plataforma Continental, Art. 2).

La identificación de la zona de las 200 millas con las aguas territoriales implicaría el ejercicio de 
las prerrogativas clásicas de mar territorial en cuanto se refiere a navegación, sobrevuelo, jurisdicción penal y civil, etc., es decir toda una serie de atributos que, de acuerdo con algunas opiniones, van más allá de los propósitos de la doctrina establecida, lo que bien pudiera incluir políticas de prevención de la contaminación y la reglamentación de la investigación oceanográfica y otras materias conexas. Sin embargo, el Brasil ha asumido todas estas prerrogativas, mientras que países como la Argentina y el Uruguay reconocen dentro de las 200 millas de mar territorial la libre navegación y sobrevuelo a partir de las 12 millas. Es hacia un régimen de este tipo que se inclinan la Declaración de Santo Domingo y. la opinión del Comité Jurídico Interamericano. $Y$ de allí han surgido conceptos tales como los de "zona económica" o mar "patrimonial" o "nacional" como términos sugeridos que pudieran ser capaces de salvar la importante objeción hecha por las grandes potencias marítimas en nombre de la libertad de comunicaciones a fin de obtener un número suficiente de votos para triunfar en la próxima conferencia mundial o para bloquear fórmulas que pudieran dejar de reconocer los principios de nuestra posición. Entre las expresiones propuestas la de "mar nacional" parecería, tal vez, la más satisfactoria para los territorialistas, ya que implica el dominio y el derecho de los Estados costeros a legislar respecto de la zona.

Esto no hace sino demostrar que la connotación ordinaria de los términos hasta ahora empleados en el derecho internacional, puede resultar inadecuada en algunos casos para expresar nuevos conceptos. Péro como lo que realmente importa es el contenido $y$ el alcance de las cosas $y$ de lo que se quiere expresar, la adaptación de los términos para adecuarlos con exactitud a los nuevos conceptos, se torna en un problema de semántica o de revisión de la definición de estos términos.

Frente a la próxima Conferencia sobre el Derecho del Niar.

Nos encontramos en vísperas de la 111 Conferencia Mundial sobre el Derecho del Mar, en la que dos tendencias principales se enfrentarán respecto a la anchura del mar adyacente sobre el cual el Estado costero puede ejercer derechos y la naturaleza de tales derechos. La vieja escuela, representada por las antiguas potencias colonialistas de Europa, Japón y los Estados Unidos, mantiene que cada Estado costero tiene un mar territorial que debiera permanecer tan estrecho como sea posible, y que el área más allá de estos estrechos linderos forma el alta maı que debiera ser libre para que todos la utilicen' $y$ exploten a su albedrio, a pesar de que las medidas de conservación de pesca, igualmente aceptables para todos, debieran ser negociadas e implementadas toniendo en cuenta el interés común.

Las ideas básicas de la escuela progresista son de que el zócalo continental, el fondo oceánico $y$ el mar que lo cubre constituyen un todo orgánico $y$ ecológico sobre cuyos recursos orgánicos $y$ minerales, de los cuales, incluso, por lo tanto la pesca, el Estado costero debiera ejercer derechos soberanos hasta una distancia razonable, dependiente de las correspondientes condiciones locales, tanto geográficas, cuanto geológicas, biológicas y económicas. De los países que apoyan esta escuela de pensamiento, son los latinoamericanos con un límite establecido de 200 millas, los que se han convertido en sus líderes $y$ los que subrayan la necesidad y el derecho de los habitantes de la tierra contigua al uso de los recursos marinos, para su propio desarrollo $y$ bienestar. Ellos afirman, igualmente, que antes que cualquier ley existió la relación natural entre el mar, sus recursos, la tierra y el hombre, y que es la presencia de este último lo que ha dado origen a su derecho como una necesidad inherente y un atributo, a la vez, de la población del Estado costero.

La asociación con estas ideas de parte de países de otros continentes que han extendido de algún modo los límites de su jurisdicción marítima, o que apoyan en todo caso el límite de las 200 millas - la República Popular China $y$, mediante una sucesión de reuniones, países de Africa, Asia y América Latina $y$ por entidades técnico-jurídicas tales como el Comité Jurídico Interamericano- es prueba tangible y concluyente del grado de aceptación internacional logrado por lo que ahora bien puede denominarse una "doctrina marítima" lo suficientemente madura como para ser admitida como institución en el nuevo derecho del mar: la zona de las 200 millas. Un rico campo de razonamiento legal se ha desarrollado de esta suerte, el que va más allá de los conceptos tradicionales $y$ funda los derechos proclamados por los Estados costeros en un título natural derivado de su posición geográfica.

Esto, en pocas palabras, es lo fundamental de las ideas de un "derecho de conservación" o de un "derecho de auto-ayuda", o de un "derecho de autoprotección", invocado sin distinción para justificar 
la posición adoptada por el Perú y otros Estados. Ciertamente que no se trata de un invento arbitrario. El mar territorial, con sus clásicos linderos, existe $y$ fue instituido en virtud del concepto del derecho del Estado a la conservación. De este modo, la noción tiene un origen común $y$ es claramente afín al principio de auto-defensa.

Tal vez nadie haya enunciado con mayor lucidez la esencia legal de estos conceptos que el eminente estadista norteamericano Elihu Root, cuando en 1914, dijo en relación a la Doctrina Monroe: "La doctrina [Monroe] no es derecho internacional. pero se basa en el derecho de auto-protección, $y$ este derecho es reconocido por el derecho internacional. .. Hállase bien entendido que el ejercicio del derecho de auto-protección puede $y$ frecuentemente? extiende sus efectos más allá de los límites de la jurisdicción territorial del Estado que lo ejerce.... el principio que sustenta la doctrina Monroe... es el derecho de todo Estado soberano a protegerse previniendo un estado de cosas en el que de no actuarse oportunamente llegaría a ser tardía cualquier acción protectora".

Esta alusión a la doctrina Monroe resulta por más de un concepto pertinente. Son notables, en efecto, las afinidades que se descubren entre la doctrina Monroe $\mathrm{V}$ los nuevos principios en el derecho del mar. Formulada hace cerca de 150 años para excluir del continente americano cualquier acción colonizadora de las potencias europeas, la doctrina Monroe, como ahora las proclamaciones de que nos ocupamos, segregó unilateralmente de la acción de otros Estados una considerable área del mundo. Objetóse, en su tiempo, el derecho de los Estados Unidos para erigirse en único intérprete de la doctrina proclamada. Pero al cabo la aquiescencia de las grandes potencias no dejó duda alguna respecto de la validez de la nueva doctrina. Puede asi decirse de las nuevas teorías en el derecho del mar to que alguna vez se dijo, con razón, de la doctrina Monroe: que les es inherente "un principio vital que se adapta con la flexibilidad de una planta en crecimiento a las sucesivas condiciones que encuentra".

La confrontación en la próxima Conferencia mundial de las dos corrientes de pensamiento mencionadas más arriba se realizará bajo condiciones muy diferentes de las que existieron cuando las Conferencias de 1958 y 1960. Alrededor de 140 Estados soberanos tomarán parte, 113 de ellos costeros. La emergencia de las antiguas colonias como Estados independientes hará que los grupos de paí- ses del tercer mundo se conviertan en un factor decisivo para llegar a una resolución. Una mayoría de los dos tercios signiticaría 94 votos. Por otra parte, 47 ó 48 votos bastarán para bloquear cualquier decisión. En base de lo que he dicho puede asumirse que este número de votos lo obtendrían fácilmente los países en desarrollo que presionan por la comprensión $y$ admisión de su posición. De cuadros al día se desprende que no menos de 27 países han extendido expresamente su jurisdicción marítima más allá de las 12 millas. A estas cifras se puede agregar aquellos países que han expresado su adhesión a nuestras ideas.

\section{Conclusión.}

A la luz de estas consideraciones y sin haber mencionado, mucho menos examinado, no pocos de los aspectos de derecho del mar que se debatirán en la próxima Conferencia, creo que es tiempo de dar fin a esta disertación sobre la doctrina de las 200 millas, en la esperanza de que los principios fundamentales que sustentan nuestra tesis sean reconocidos en alguna forma por la comunidad de naciones. Son principios de una filosofía socio-económica que persigue el establecimiento de un orden más justo para el uso $y$ explotación de los mares como un factor en la paz, bienestar y equidad de todas las naciones del mundo. La vieja institución del mar territorial debería ser cambiada o dar lugar a una división diferente de los océanos, de acuerdo a las necesidades y realidades de nuestro tiempo, sin detrimento de las necesidades de las comunicaciones internacionales, y de que se reconozca a los Estados costeros el derecho de soberanía sobre sus mares adyacentes. La aceptación mundial de una fórmula que reconozca estos derechos, tal vez mediante una pluralidad de sistemas, es lo que esperan los paises en desarrollo que luchan por una idea humanista $y$ socio-económica con suficiente base jurídica.

Mientras tanto, es cuanto cabe de significativo el que la última Asamblea General de las Naciones Unidas (1972) haya votado a favor de una propuesta presentada por Islandia $y$ el Perú, confirmando que los Estados tienen un derecho permanente de soberania sobre todos sus recursos naturales, incluyendo no sólo los que se encuentran en el lecho del zócalo continental, sino también en las aguas suprayacentes. Esta propuesta fue adoptada mediante Resolución No. 3016 el 18 de diciembre de 1972, por 102 votos a favor, ninguno en contra y 22 abstenciones. Sería muy grave si los debates en la próxima 
Conferencia no alentaran la consolidación de estas ideas y un ordenamiento más justo del derecho del mar. Una actitud inflexible por parte de la Conferencia no tendría la posibilidad de detener el proceso. Las normas establecidas y en vigor por más de 25 años han ganado terreno y respetabilidad, y se puede decir que ya tienen la fuerza de la costumbre y están investidas de la claridad y justificación que debe tener cualquier norma jurídica. Continuarían en vigor, entonces, ganando aliados. Porque si la providencia ha puesto en el mar, al alcance de los Estados costeros, recursos que les pertenecen por razones a priori de proximidad, el acceso a estos recursos no debiera serles denegado $-\gamma$ aún menos a los paises en desarrollo. El caso del Perú sirve de ejemplo de racional utilización de estos recursos, de tal suerte que otras naciones en desarrollo bien pudieran seguirlo para utilizar sus propios recursos y elevar el nivel de vida de su población sin incursionar en mares extranjeros.

Nuevos vientos soplan a través de los océanos $\gamma$, lejos de ser aquellos contrarios, cada día son más propicios en nuestro favor. 